\title{
The Analysis of the Folk Lending in Linxia Hui Autonomous Prefecture
}

\author{
Yueliangfan $\mathrm{Li}^{1}$ \\ ${ }^{1}$ School of Economics, Northwest University for Nationalities, Lanzhou, China \\ Correspondence: Yueliangfan Li, Tutor, School of Economics, Northwest University for Nationalities, Lanzhou, \\ China.
}

Received: June 23, 2016

Accepted: July 6, 2016

Online Published: August 17, 2016

doi:10.5430/jms.v7n3p10

URL: http://dx.doi.org/10.5430/jms.v7n3p10

This work was supported by the Fundamental Research Funds for the Central University of Northwest University for Nationalities (Grant No: 31920150118)

\begin{abstract}
Linxia Hui Autonomous Prefecture is a Muslim community in China, driven by the Mercantilist ideas of Islamic finance, whose financial industry presents the fast growth momentum in recent years, and the private lending activities are prosperous and frequent. This paper, by using the method of questionnaire and on-the-spot investigation of the region, makes a detailed analysis of the present status quo of this informal finance, the existing problems in the private lending, as well as the causes of such problems, the specific use of folk lending in the region, lastly, the article puts forward the corresponding solutions and suggestions.
\end{abstract}

Keywords: folk lending, Islamic finance, informal finance, Muslim community

\section{Introduction}

Folk lending, namely, folk credit, refers to the loan business takes place among the natural persons, legal persons and other organizations, rather than the financing behavior of financial institutions and their branch offices established upon the approval of the financial supervision and regulation department.

Private lending exist in various forms in different regions all over China, because different ethnic groups have the different characteristics in history origin, mode of production, language, culture, customs and other aspects. Among them, under the influence of the Islamic culture, Muslims folk lending plays a positive role in economic and social development, which has gradually aroused the concern of the academia and the relevant departments. This paper takes Linxia Hui Autonomous Prefecture, as an example, and analyses the folk lending conditions in Muslim settlement region.

Linxia Hui Autonomous Prefecture is one of two main Hui autonomous regions in China, established in November, 1956.LinXia is located in the upstream of the Yellow River, which is an important commodity distributing center in the southwest of Gansu province and sino-tibetan trade hub.

Islamic culture encourages business, under the influence of mercantilist culture, Linxia financial market is prosperous, while the active development of the folk financing, to a great extent, makes up for the deficiency of the formal financial development, and plays an important role for its regional economy. Folk financing operation is easy and flexible to meet the needs of the development of private economy, at the same time, it can cater to the capital demand of the individual businesses, the urban and rural residents, as well as reduce the negative influence of the fault of county financial system, greatly improving the efficiency of the social idle funds, and promote the economic development of Linxia region.

This paper endeavors to explore the effects, the advantages and disadvantages of the folk lending in the economic development in Muslim region, and puts forward the corresponding countermeasures and suggestions. The author hopes to find out the problems existing in the process of microfinance development, and the suitable model for local development, speeding up Linxia's economic development.

This paper is organized as follows. Section 2 presents an introduction and detailed analysis of the questionnaire survey. Section 3 illustrates the characteristics of the folk lending in this region. Section 4 points out the existing problems. And section 5 will be the relevant suggestions. The last section is the conclusion and implications. 


\section{The Questionnaire Survey Content and Result Analysis of the Folk Lending in Linxia}

\subsection{The Overview of the Questionnaire Survey}

There are 1 city and 7 courtiers in Linxia Hui autonomous prefecture, and a total area is 8169 square kilometers as well as a total population is 2.1635 million, which is a multi-ethnic, multi-religious coexistence place, there are 22 minority nationalities, including Hui, Dongxiang, Baoan, Salar etc., accounts for $56.4 \%$ of the total population.

The total GDP of Linxia reached 116.742 billion yuan in 2015, GDP per capita is 8588.86 Yuan, which ranks the 14th in Gansu province, while the rate of economic growth, 9\%, one of the the fastest in the whole province. Because of the lack of corresponding financial support services, and local financial market can not fully meet the demand of local residents' financial activity, which, therefore, stimulates the local folk lending activities.

The research surveys the local financing participants, reason, interest rate etc.by the designed questionnaire to understand the present status quo of the local folk financing and existing problems. It takes 45 days to design the questionnaire, organize the issuance, and carry out the data processing. We distributed 750 questionnaires and finally collected 615 effective questionnaires. It shown that $86 \%$ of respondents were Muslim, including Hui, Dongxiang, Salar, Bonan, etc. About $56 \%$ of the respondents live in urban areas, and $56 \%$ live in town. In addition, among all the respondents, individual businesses and workers accounted for the most, $35 \%$ and $32 \%$ respectively, and followed by civil servants and farmers, accounted for $13 \%$ and $12 \%$, while the respondents engaged in the financial sector accounted for $8 \%$.

\subsection{The Analysis of the Present Status Quo and Characteristics of the Folk Lending Development in Linxia}

\subsubsection{Understanding of the Private Lending}

Questionnaire survey results show that the inhabitants of the region have a relatively narrow understanding of the folk lending, not comprehensive. (Chart 1)

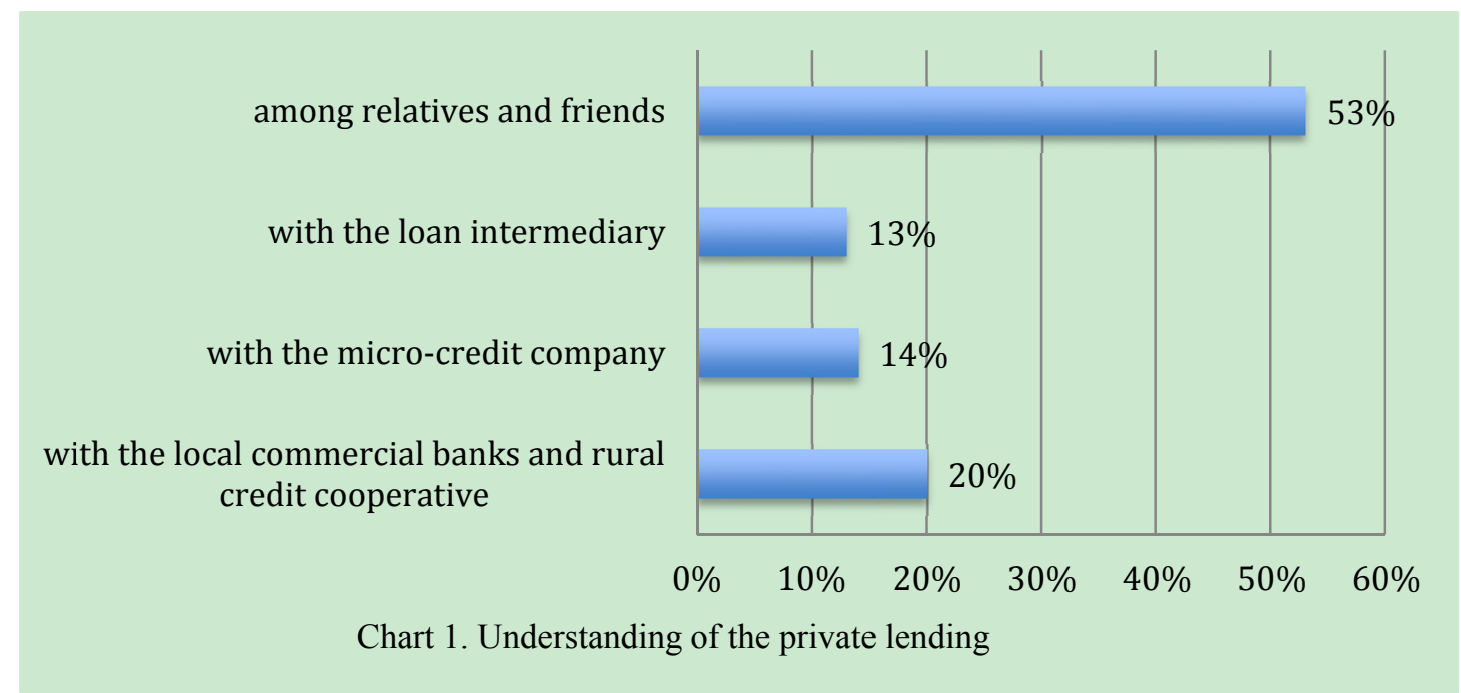

Most people agree with personal debt belongs to the folk lending, and regard the corporate lending, such as small loan companies, as the folk lending. In addition, $20 \%$ of people think that the loans from the local commercial banks and rural credit cooperatives also belong to the folk lending, in fact, such lending behavior from the formal financial institutions does not belong to the folk lending. Therefore, many respondents are still unclear about the folk lending.

\subsubsection{The Participation of Folk Lending}

According to the survey, $78 \%$ of respondents take participation in the private lending between relatives, friends and micro-loan companies, and $67 \%$ of these participants have been involved in the disputes in such lending activities.

\subsubsection{The Characteristics of Counterparties in the Folk Financing Activities}

Based on the aforementioned data, among these respondents who have participated in the private financing, we find that the number of people have the activity of borrowing accounts for $53 \%$ among all the respondents, and people involved in lending activities accounts for $47 \%$.Among the borrowers, the majority, $57 \%$ choose to borrow funds from relatives and friends, while $31 \%$ of the lenders tend to give the loan to their relatives and friends. The author considers this kind of choice derives from the establishment of a trust based on the closet relationships, blood 
relationship and friendship, in most cases, people are more likely to borrow money from the people who are more familiar with, with the chances of success increase. In addition, the total number of borrowers who borrow from the folk intermediary institutions make up for $26 \%$, while the proportion of the lenders who makes money loaned to the folk intermediary is $31 \%$.Based on this visit, most so-called folk intermediary institutions there are commonly some small local agencies, such as the pawnshops, guarantee investment companies etc., whose loan procedures is simple, and the cost is relatively low.

However, as for the money is loaned to the intermediaries, the lenders can obtain a more considerable income, because the interest rate of the intermediary institutions generally higher than that of formal financial institutions. It is important to note that such lending usually belongs to the short-term loans, which is more safe and reliable, rarely the long-term loans. At the same time, only $14 \%$ of the borrowers tend to borrow from the loan company, while $27 \%$ of the people who choose to lend money to the loan company. The operating process of such loan company is relatively complicated, and lending standard is tighter, which generally requires a certain amount of collateral, whose types, quantity, qualification should be strictly conform to the requirements of the company, indicating that such lending behavior belongs to the medium and long-term capital raising. Of course, the local people also have the other way of financing, but the proportion is very small. (Chart 2, Chart 3)
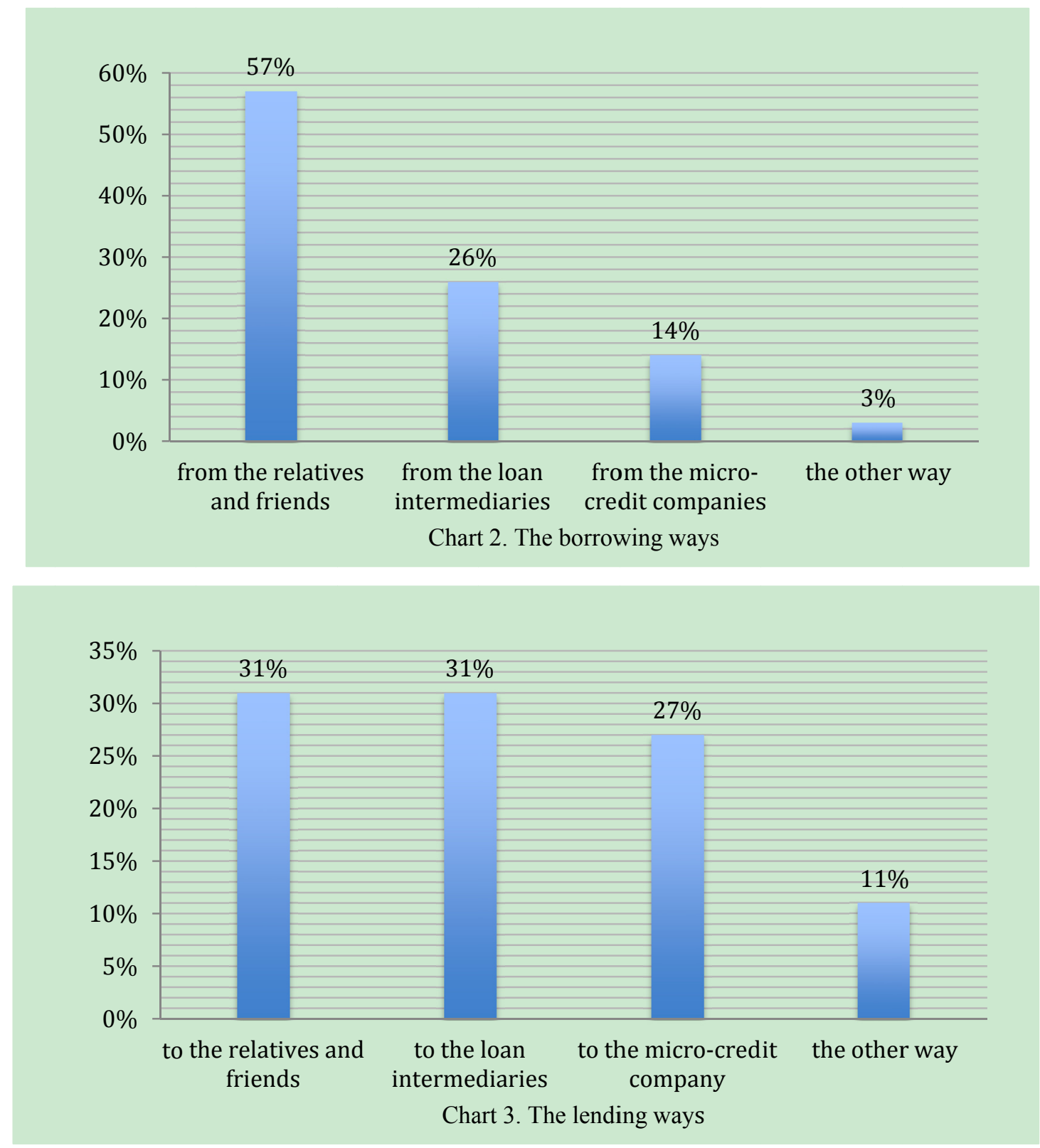


\subsubsection{The Borrowing-Lending Approach}

Among the prosperous private lending activities, the borrowing-lending behavior of most people belongs to the unsecured type. The borrowers involved in unsecured loans account for $55 \%$ of the total, and the proportion of the lenders of the unsecured loan is as high as $70 \%$. The reason lies in that the borrowing-lending practices of the most people take place among relatives and friends, which is a kind of mutual-aiding financial activities actually. Such practices, which take place between the local residents, is generally based on the civil contractual relationship, and then generates the creditor-debtor relationship between the participants. In terms of China's current legal status, there are no clear rules to regulate such informal sign, featured by verbal agreement or informal written agreement, in addition, witness by a third party can also make the agreement of the force.

It is obvious that such informal and simple agreement appeals to many participants, since it is easy to operate, cost-saving and time-saving. On the other hand, in spite of the default, it may be the other direct cause to bring about the economic disputes, because of the unspecified particulars and lack of the legal effect.

\subsubsection{The Motivation of the Borrowing-Lending Activities}

Among the above-mentioned borrow practices, the proportion of the residents who borrow money for the purpose of purchasing a house is the largest, about $34 \%$, because a great deal of money is needed to afford a house, it is hard for a common family to meet the demand only on their own resources.

Besides, $28 \%$ of the people involved in borrowing use the money for the productive cycle, and $18 \%$ of the people borrow money in order to see a doctor. In addition, $8 \%$ of the residents choose to use informal financing activity to solve the problem of children education. In addition, there are $8 \%$ of people choose to borrow money to invest and finance. (Chart 4)

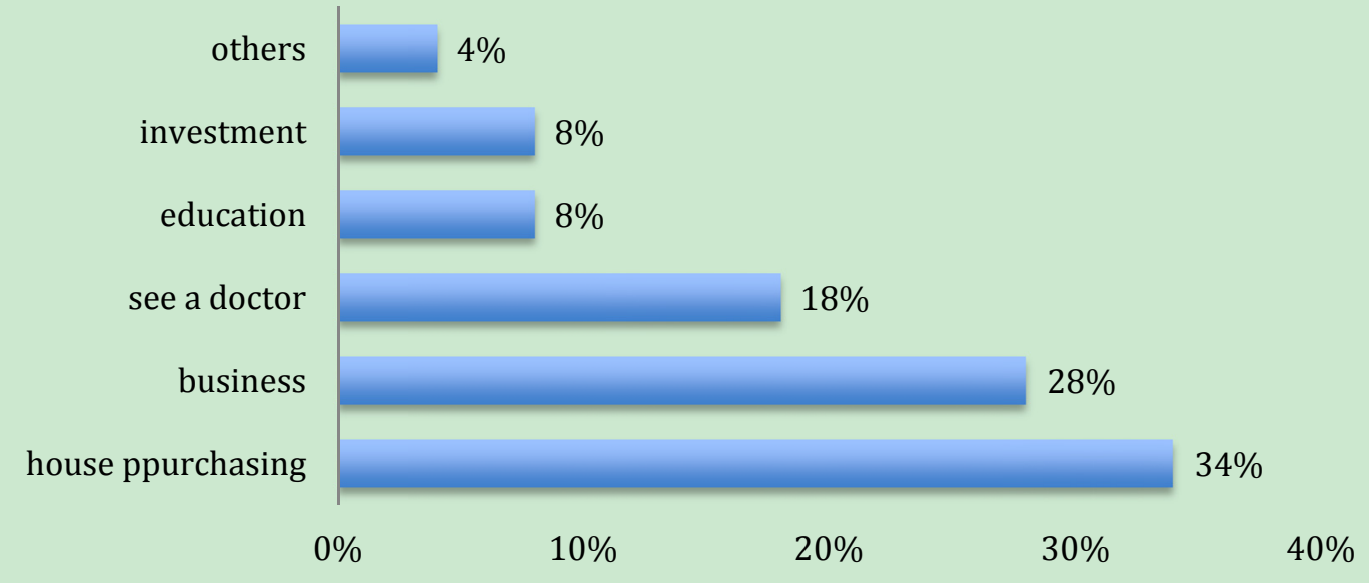

Chart 4. The Purposes of Borrowing

And $42 \%$ of the lenders tend to help friends and family, while $38 \%$ of lenders choose to lend to the institutions because of the high interest rates.

\subsubsection{The Amount}

According to the survey, the percentage of borrowing and lending amount less than 10000 yuan is $29 \%$ and $32 \%$, respectively. The amount ranges from 10000 yuan to 100000 yuan account for $34 \%$ and $51 \%$ of the total respectively. The participants who choose to borrow money ranged from 100000 yuan to 300000 yuan account for $35 \%$ and $16 \%$. The author thinks that microcredit, which accounts for a large proportion, generally takes place among the relatives and friends, in contrast, the percentage of the lending amount more than 100000 yuan dropped shortly since the loans are mainly used for the purchase of personal property, real estate or operation of business cycle, generally belong to the medium and long-term types, although the loan demand has increased, the lenders begin to think and act carefully in order to prevent the default risk. In addition, the proportion of the borrowing and lending amount more 
than 300000 yuan is only $2 \%$ and $1 \%$, obviously, the participants has been very few, the borrower may consider the repayment capability and make a prudent decision, or they fail to match the counterparty to make a deal, only to change the decision finally. Most lenders will not easily lend so much money and they may push up lending standards, and check all aspects of the qualifications of the borrowers strictly, then decide whether to lend. It is likely for the big lenders to lend money to the reputable private lending institutions, so as to obtain reimbursement guarantee and high interest repayment. (Chart 5)

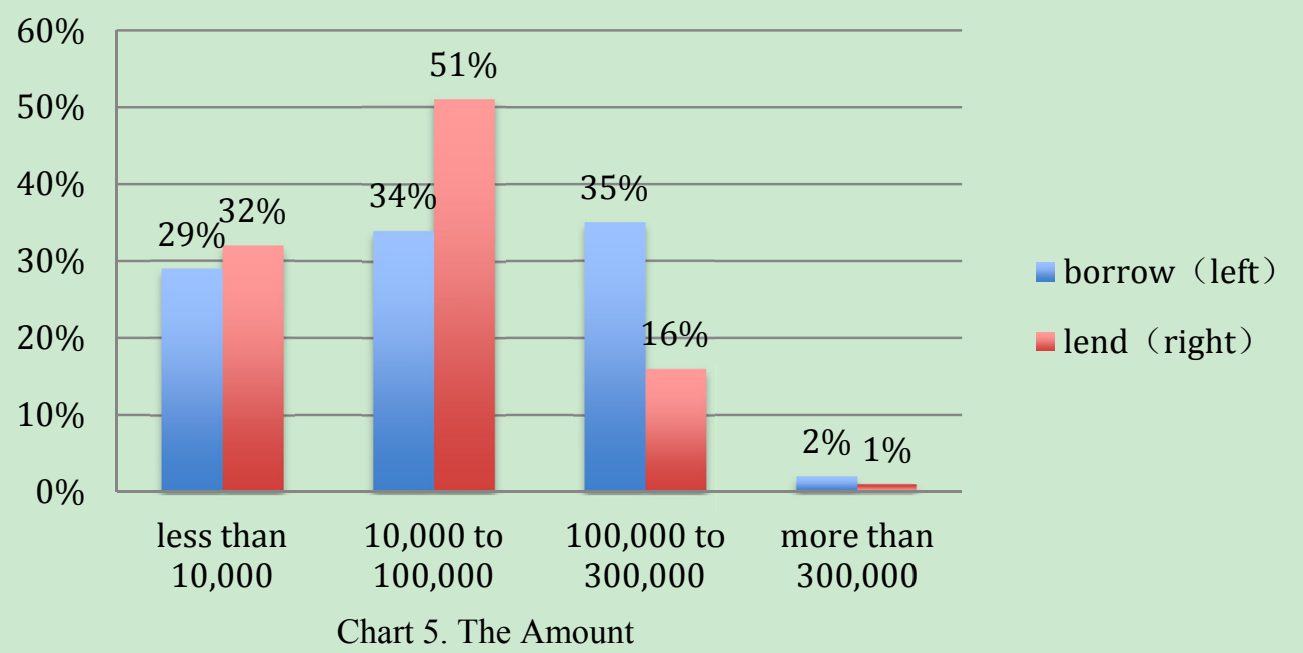

\subsubsection{The Interest Rate}

Supreme judicial interpretation of the interest rate in the folk lending is very clear, and it states that more than $36 \%$ at an annual rate of loan contract is invalid, beyond the legal protection.

In this research, the data demonstrates that the most private loans among relatives and friends belong to interest-free loan, and such lending is very popular, $56 \%$ of borrowers and $36 \%$ of lenders favor this form. Dealing with the private lending companies, by contrast, generally applies to the interest rates below $10 \%$, and $32 \%$ of borrowers compared with $43 \%$ of the lenders prefer this deal, whose interest rate range is acceptable. Obviously, the borrowers feel pressure when the interest rate from $10 \%$ to $36 \%$, only $8 \%$ of borrowers and $11 \%$ of lenders tend to choose this level. As for the interest rate more than $36 \%$, which has become a veritable usury, such lending is not protected by the laws, in this case, it is less likely for the lenders to make loans, while the borrowers are sometimes forced to borrow because they are compelled against their will. (Chart 6)

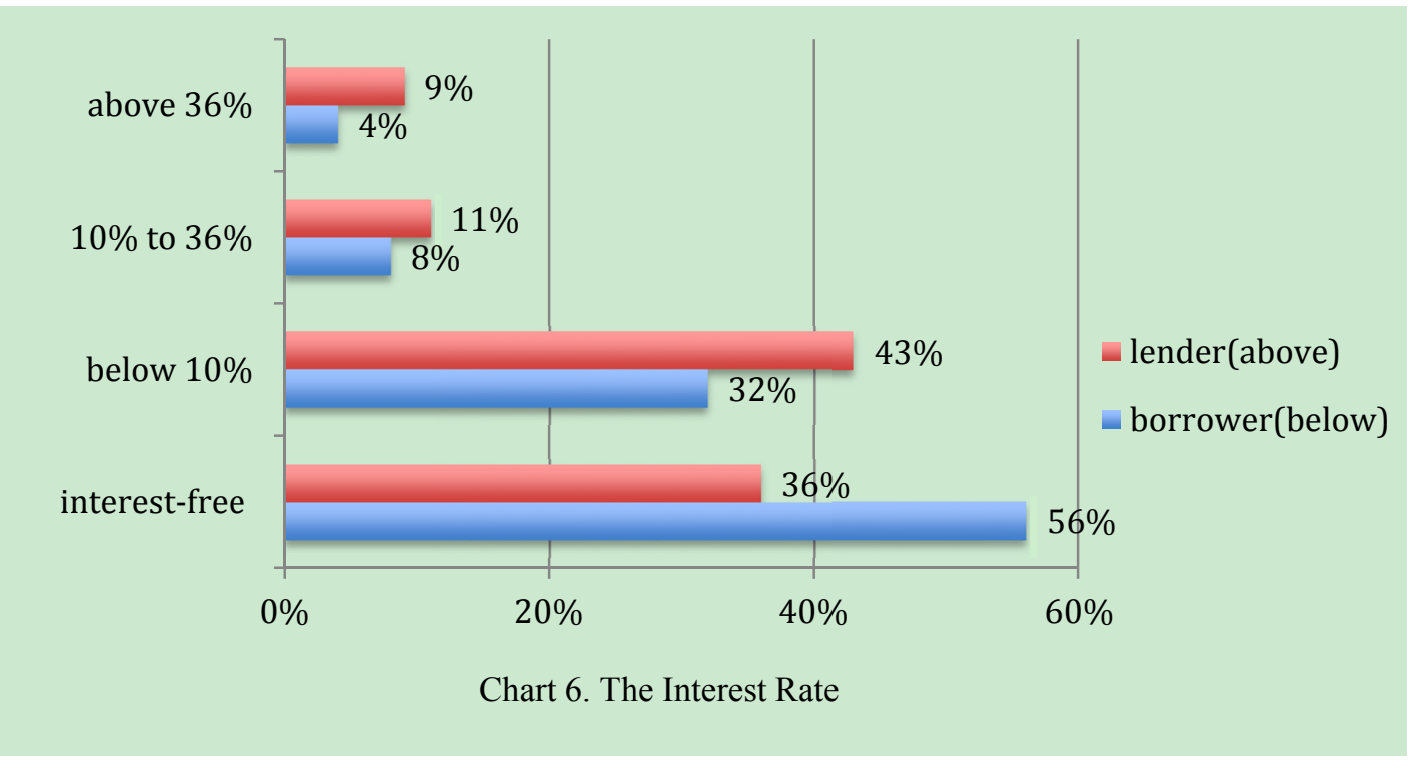




\subsubsection{The Disadvantages in the Folk Lending}

According to the survey, the majority of the participants believe the high interest rates, the high risk of default, non-standard loan pattern are main disadvantages, besides, $17 \%$ of the participants believe the related legal and regulatory system are not perfect, and $6 \%$ of the respondents consider the informal lending may affect the borrowers adversely, which increase their burden.

\section{The Characteristics of the Folk Lending in Linxia Region}

Firstly, there is a high demand in capital from the local residents, and the folk lending activities are really active. LinXia is commonly known as Mecca of China, the ethnic residents are good at business by adhering to business ideas and business models of the Islamic culture, driving the capital needs increase year by year. According to data, in 2014, the direct or indirect financial credit funds reached 3.56 billion yuan in Linxia.

In addition, the local people value the relationships, if some people achieved some success in the trade industry, they are willing to lead the villagers to the common prosperity, thus the mutual actions can make more people involved in commerce and trade circulation industry rapidly. It is no doubt that these people constitute the main body of private lending, driving an extraordinary folk financing based on the personal credit in Gansu Province, favored by the local residents.

Secondly, the private lending really makes up for the deficiency of the formal financial in terms of financial support. Restricted by the factors of geography, history, culture, traditions, customs and others, the local economy development is at a relatively slow speed and a low level, whose main economic indicators rank the last among 30 national minority autonomous prefectures and 14 provincial cities, with the develop gap widening.

Although more and more state-owned commercial banks gradually began to set up the branches in Linxia, because the authorization is not high, in fact, the county financial support is very limited, which cannot meet the fund demand for education, health care etc. The problem of single financial institution and the shortage of financial support reinforce vicious circle, forcing financial institutions to further increase the loan interest rates, therefore, the bank support for the impoverished residents is relatively poor. At this point, the folk financing, to a great extent, can solve the financial difficulties.

\section{The Existing Problems in the Private Lending}

\subsection{The Private Lending Is Not Standardized}

Although the operation of the private lending is easy to handle, and there is no restrict requirements for the collateral, such borrowing drift from the law regulation, the participants are easily caught in the debt disputes, which endanger the market order and social order. In addition, some cases of deceive by the loan intermediaries take place in some areas in Linxia, leaving both sides of participants suffered from the great loss. Finally, the investment direction of the fund gain from the folk financing is difficult to control, which easily causes the serious consequences, such as illegal fund-raising. And the most folk lending behavior is based on the personal credit and lack of normal collateral, the risk of default is much higher than that of the formal financing.

\subsection{The Credit Risk Is Hard to Control}

In Linxia region, generally speaking, the networks form the basis for the informal lending. The networks mainly include three parts: relatives, friends and acquaintances. With the maturation of the market, the lending market expands unceasingly, the trust established in the original network has been unable to be adapt to the present lending market, and the trust mechanism is more and more vulnerable. In the aspect of risk prevention, the role of this mechanism is more and more small. In addition, considering the objective factors driving the interest rate rise, such as speculation, which are potentially increasing the risk of default.

\subsection{The Folk Lending Is Lack of Legal Protection}

In Linxia region, the lenders involved in the informal lending include local small loan companies, financing guarantee companies, pawnshops, trust companies, and financial mutual organizations, etc., such institutions belong to shadow Banks, whose operation has not yet been fully protected by the laws, easily leading to the economic disputes. The current legal regulations do not provide both a clear distinction between illegal deposits and the legal folk financing, nor the clear folk financing contract protection principle, once the two sides are caught in the financing debt disputes, it difficult to get legal support. The legal procedure in folk financing is not complete, and the potential risk is bigger, once the credit risks take place, the security of the borrowed money will be exposure to a serious threat. 


\section{Suggestions for the Healthy Development of Private Lending}

\subsection{Strengthening the Consciousness of Good Faith, Setting up the Concept of Prudent Lending}

Linxia Hui autonomous prefecture is an ethnic minority community, which is a relatively closed area, and many residents are poorly educated. Given this, local governments should strengthen the honesty education as well as the awareness of the risks for the residents through a variety of channels, reminding the residents should choose the reputable formal company to borrow, offer relevant personal credentials, and cooperate with the agency to evaluate the value of the mortgage or the pledge. As for the borrowers, it is crucial for them use the fund rationally and arrange the repayment schedule properly after they get the money, and negotiate with the loan company when some emergencies occur. In terms of the lenders, it is significant for them to clear the intention of the borrowers and entrust the relevant qualified guarantee company to guarantee the loans, and then carefully make a decision to avoid the bad consequences.

\subsection{Strengthening the Construction of Credit System}

The local financial management office needs to actively contact the prefecture-level branch of the People's Bank of China and China Banking Regulatory Bureau, making the activities of the local loan companies involved in the credit system and the credit information of borrowers available, constantly strengthening the risk-control abilities of the microfinance company. Under the wave of the Internet, the government, the courts and the major online payment platform should be closely linked with each other, to establish personal and enterprise credit files, and give grant to the relevant institutions the permissions to view the credit archives of potential lenders, thus to kill the bad loans in the bud and take preventive measures.

\subsection{Establishing a Diversified Multi-level Financial Service System}

From this investigation, we found that the local farmers are also potential borrowers, whose borrowing needs are matched with the periodic characteristics of agricultural production. Suffered from the lack of relevant credentials, the peasants are unable to gain the funds for the agricultural production. Seen from this, it is urgent to develop the inclusive finance, which require us to actively explore to establish multi-level financial service system, vigorously carry out product and service innovation, serving the small and medium-sized enterprises and the social vulnerable group, and establish the scientific and reasonable loan standards, facilitating the residents who are qualified and in urgent need of money, to obtain loans in a convenient and quick way.

\subsection{Perfecting the Laws and Regulations to Purify the Folk Lending Market}

So far, China have issued a series of related management regulations for folk lending, and LinXia government needs to publish relevant supporting measures to guide the normal development of the local folk lending, in addition, the justice department should step up efforts to hit the illegal financial activities, such as the usury, underground banks, illegal fund raising etc., to purify the market, supporting the healthy development of the financial institutions and the real economy. Government should, in accordance with the principle of classification management and differential treatment, carry out special projects to the local loan companies from the market access, the daily supervision and administrative penalty, and clean, outlaw the companies which adsorb the illegal public deposits and distribute high-interest loans, more seriously, transfer the suspected companies to the judicial organs.

\section{Conclusion}

We use the questionnaire investigation to study the folk lending situation in Linxia Hui autonomous prefecture, and this article analyses the characteristics and problems of the private lending market, and puts forward the corresponding suggestions. Based on the above analysis, the author thinks that, as an ethnic minority community and an important business area, giving full play of the folk financial activities is an effective complement to the formal finance. Under the trend of the Internet wave, establishing perfect credit archives, making the borrowers qualifications available, matched with a powerful government regulation, as well as the prudent personal financing behaviors, we believe that the private financing can better serve the real economy, and promote the prosperity and harmony of Linxia Hui autonomous prefecture.

China is a big family with 56 ethnic groups, we regard the study of Linxia area as a scope, which will encourage us to proceed our survey for the other ethnic minority communities, and then we will take further steps to deepen the research and make contribution to the economic sustainable development of these regions.

\section{References}

He, J. (1992). The research on the standardized development of the folk financing in China. The Journal of Quantitative \& Technical Economics, 8(8), 24-27. 
Li, B. (2012). Discuss the pros and cons of private lending. Business Information, 21-22.

Li, J., \& Sha, L. (2005). The research on the National consciousness of internal experience and external behavior. Guangxi Minorities Research, 20-33.

Li, P. (2015). The research on the financial ecological environment in Linxia hui autonomous prefecture. Regional Economy Study, 3-16.

Qian, Y., Ma, L., \& Li, R. (2012). Introduction to contemporary rural folk lending and national law. Investment and Business, 11-13.

Wang, X. (2013). Chinese provincial folk financing scale estimate: 2010-2015. Social Economy Research, $12-14$.

Xin, C., Wang, F., \& Kai, W. (2014). The research on the financial support for poverty problem. Finance and Investment, 3(3), 17-19.

$\mathrm{Xu}, \mathrm{M}$. (2011). The economic analysis of the folk lending in Wenzhou city: based on the analysis of the financial repression theory. Business Information, 26-29.

Zhang, J. (2015). The investigation and thinking of the folk financing problems in the ethnic areas. Gansu Finance, 27-29.

Zhang, Y., \& Li, A. (2015). The study on the informal finance of the northwest ethnic areas. Minority Economic Research, 3, 11-15, 21. 